\title{
The Interplay between Accounting and Reporting on Mitigation Contributions under the Paris Agreement
}

\begin{abstract}
Kelly Levin*
This paper explores the linkages between accounting for and reporting on mitigation contributions under the Paris Agreement. Specifically, it explores the relationship between the provisions related to communicating nationally determined contributions (NDCs) under Article 4, paragraph 8; accounting for NDCs under Article 4, paragraph 13; and reporting on progress and achievement made on NDCs under Article 13, paragraph 7(b). It finds that there are significant consequences if progress made on these different elements is uneven; if a weak outcome is reached on one of these provisions, the integrity of the Agreement will rest on greater progress made on the other provisions.
\end{abstract}

\section{Introduction}

Under the Paris Agreement, Parties put forward their contributions to address climate change in the form of Nationally Determined Contributions (NDCs). The NDCs embody efforts by each country to reduce national emissions and adapt to the impacts of climate change. The concepts of 'contribution' and 'national determination' are reflected in Articles 3 and 4.2 of the Paris Agreement, which are based on the premise that each government decides, based on its own circumstances and capacities, the actions it will take to contribute to achieving the objectives of the Agreement. The efforts of individual Parties to reduce national emissions should, in aggregate, set the world on a path to limit average temperature rise to well below $2^{\circ} \mathrm{C}$, or aspirationally $1.5^{\circ} \mathrm{C}$, above pre-industrial levels, the long-term goals of the Paris Agreement. As of August 2018, 194 Intended Nationally Determined Contributions (INDCs) or NDCs have been submitted. ${ }^{1}$

The Paris 'rule book' is to be agreed at the $24^{\text {th }}$ session of the Conference of the Parties (COP24) to the UNFCCC by the Conference of the Parties serving as the meeting of the Parties to the Paris Agreement

DOI: $10.21552 / \mathrm{cclr} / 2018 / 3 / 6$

* Kelly Levin, Senior Associate, World Resources Institute. For correspondence: <klevin@wri.org>

1 This figure counts the individual European Union [EU] member states and the European Union itself.
(CMA) in Katowice, Poland. It will operationalize the provisions of the Paris Agreement, and several components of this rule book will establish the guidance, modalities, and procedures for understanding Parties' NDCs and progress made towards achieving them.

This article explores three interrelated provisions of the Paris Agreement that have relevance for understanding NDCs and their achievement:

- Communication of the NDCs: Article 4, paragraph 8 of the Paris Agreement states that in communicating their nationally determined contributions, all Parties shall provide the information necessary for clarity, transparency and understanding in accordance with decision 1/CP.21 and any relevant decisions of the CMA;

- Accounting of the NDCs: Under Article 4, paragraph 13 of the Paris Agreement, Parties are to account for their NDCs and, in doing so, promote environmental integrity, transparency, accuracy, completeness, comparability and consistency, and ensure the avoidance of double counting; and

- Reporting on progress and achievement of NDCs: According to Article 13, paragraph 7(b), Parties are to provide information necessary to track progress made in implementing and achieving its nationally determined contribution under Article 4 .

The first section of the article is dedicated to a brief description of each of these three provisions. The ar- 
ticle then turns to an exploration of the linkages among these provisions and argues that if the rulebook is not uniformly robust across all of the provisions, it will need to be strengthened for the other provisions accordingly, with resultant tradeoffs.

\section{Communication of NDCs}

The Paris Agreement requests Parties to prepare, communicate and implement NDCs every five years. Successive NDCs are to represent a progression beyond the current one, and Parties are to take into account the results of the global stocktake under the Paris Agreement, a process by which the international community will evaluate progress towards achieving the objectives of the Paris Agreement.

When communicating their NDCs, per Article 4 paragraph 8, Parties are to submit information necessary for clarity, transparency and understanding (CTU) of the NDCs. If CTU is sufficiently detailed, it can allow for holding Parties accountable to their NDCs and help with the assessment of individual and collective progress. ${ }^{2}$ With adequate CTU provisions, Parties would clarify the nature of their NDC, along with the assumptions and methodologies underpinning it. Without this information, it will be difficult, if not impossible, to understand what countries have committed to and track progress and achievement towards their NDCs.

Parties are to provide information necessary for CTU of NDCs in accordance with Decision 1/CP.21, which includes a list of information that Parties may choose to include. ${ }^{3}$ This list of information elements is drawn from the Lima Call for Climate Action (Decision 1/CP.20, paragraph 14) which Parties voluntarily used to accompany the first intended NDCs. Decision 1/CP.21 further requests the Ad Hoc Working Group on the Paris Agreement to develop more guidance for the information to be provided by Parties in order to facilitate CTU. It remains to be seen whether this guidance will be more detailed, and whether Parties will embrace such guidance more than they have adhered to the foregoing elements in Decision 1/CP.21 with their initial NDCs. Significant transparency gaps exist given the lack of information accompanying many of the first NDCs, resulting from some Parties not adhering to the list of information from the Lima Call for Climate Action, as well as the list being insufficiently detailed for understanding the
NDCs. ${ }^{4}$ It is worth noting that the Lima Call for Climate Action's reference to Parties' providing information on CTU was voluntarily. The Lima decision's language stated that Parties 'may include, as appropriate, inter alia...'. In contrast, the Paris Agreement requires all Parties to provide the information necessary for CTU in accordance with Decision 1/CP.21. However, the further guidance under development could be as flexible as that in the Lima decision, or include all or some voluntary elements of information.

Parties met in informal consultations on CTU at the sixth part of the first session of the Ad Hoc Working Group on the Paris Agreement (APA 1-6), held in Bangkok in September 2018. However, the consultations did not result in a revised version of the 'tool' developed by the Co-Chairs ahead of the session. ${ }^{5}$

\section{Accounting of NDCs}

While information to enhance CTU provides information on the NDC itself, accounting of NDCs determines how to track progress towards the NDC. Accounting is the process of: determining the quantity of emissions, removals, transactions related to internationally transferable mitigation outcomes

(ITMOs), and land sector emissions and removals

2 Yamide Dagnet, Nathan Cogswell, Eliza Northrop, Niklas Höhne, Joe Thwaites, Cynthia Elliott, Neil Bird, Amy Kirbyshire, Sebastian Oberthür, Marcelo Rocha, Kelly Levin, and Pedro Barata, 'Setting the Paris Agreement in Motion: Key Requirements for the Implementing Guidelines' (2018) Working Paper. Washington DC: Project for Advancing Climate Transparency (PACT).

3 Para 27 notes that instead of 'information to be provided by Parties communicating their nationally determined contributions, in order to facilitate clarity, transparency and understanding, may include, as appropriate, inter alia, quantifiable information on the reference point (including, as appropriate, a base year), time frames and/or periods for implementation, scope and coverage, planning processes, assumptions and methodological approaches including those for estimating and accounting for anthropogenic greenhouse gas emissions and, as appropriate, removals, and how the Party considers that its nationally determined contribution is fair and ambitious, in the light of its national circumstances, and how it contributes towards achieving the objective of the Convention as set out in its Article 2; 28.

4 Thomas Damassa, Taryn Fransen, Barbara Haya, Mengpin Ge, Krisztina Pjeczka, and Katherine Ross, 'Interpreting INDCs: Assessing Transparency of Post-2020 Greenhouse Gas Emissions Targets for 8 Top-Emitting Economies' (2015) Working Paper. Washington, DC: World Resources Institute.

5 'Earth Negotiations Bulletin: Summary of the Bangkok Climate Change Conference' <http://enb.iisd.org/vol12/enb12733e.html> accessed 24 September 2018 
that may be applied toward a mitigation contribution within an NDC; calculating the target level of emissions specified by the contribution; comparing the two quantities to evaluate NDC progress and achievement; and recording and communicating the results. ${ }^{6}$

There are three stages of accounting, each with its own purposes:

- Before implementation: Accounting guidance defines 'what counts' and lays out a clear framework for assessing progress;

- During implementation: Accounting guidance defines how Parties track and report progress in a comparable and transparent manner; and

- After implementation: Accounting guidance defines how Parties assess whether their contributions have been achieved.

Accounting can also assist in ex ante aggregation of global emissions reductions and tracking progress towards Paris Agreement's global goals, enable comparability, and enable participation in internationally transferable mitigation outcomes.

Article 4, paragraph 13 requires Parties to account for their NDCs according to principles including transparency, accuracy, completeness, comparability, and consistency, while avoiding double counting. The accompanying Decision 1/CP.21 calls for the elaboration of accounting guidance, with additional specifications to consider when designing such guidance. Parties can voluntarily elect to use the guidance for their first NDC, but Parties are required to apply the guidance only to their second and subsequent NDCs. Parties are currently negotiating the contours and details of accounting guidance related to NDCs and ITMOs. Little progress was made on the accounting

6 Kelly Levin, David Rich and Cynthia Elliott, 'Recommendations for Accounting for Mitigation Components of Nationally Determined Contributions (NDCs) under the Paris Agreement' (2018) Working Paper. Washington, DC: World Resources Institute.

7 'Revised Additional Tool under Item 3 of the Agenda' <https:// unfccc.int/documents/182109> accessed 24 September 2018

8 Christina Hood and Carly Soo, 'Accounting for Mitigation Targets in Nationally Determined Contributions under the Paris Agreement' (2017) OECD/IEA Climate Change Expert Group Paper 2017/05. Paris: Organisation for Economic Cooperation and Development and International Energy Agency.

9 'Revised Additional Tool under Item 5 of the Agenda' <https:// unfccc.int/sites/default/files/resource/APA1.6_Revised\%20Too Item\%205 Revised\%20final\%20iteration v2.pdf> accessed 24 September 2018 guidance APA 1-6, the last official negotiating session before COP24. Parties were not able to consider the technical details of accounting, as there was a stalemate on broader issues related to differentiation and the scope of accounting (i.e., whether accounting was constrained to mitigation aspects of NDCs). The CoChairs' tool will now be revised to correct an omission, but did not incorporate the broader exchange in Bangkok. ${ }^{7}$ Negotiations at COP24 will be based on this tool.

\section{Reporting on Progress and Achievement of NDC}

While accounting determines how Parties should track progress and achievement of the NDCs, reporting guidance outlines the information that should be provided to allow others to understand NDC progress and achievement. In other words, accounting guidance would stipulate how Parties track NDC progress and achievement, while reporting guidance would stipulate what information Parties report regarding NDC progress and achievement. ${ }^{8}$ Ideally, information provided for CTU of NDCs is sufficient enough to be the basis of both accounting and reporting of progress during and after NDC implementation.

Article 13, paragraph 7(b) requires Parties to regularly provide information necessary to track progress made in implementation and achievement of NDCs, and according to Article 13, paragraph 13, the CMA is to adopt common modalities, procedures and guidelines for such reporting. Parties are currently negotiating the scope and details of such reporting requirements.

The co-facilitators of the negotiations on this item were able to revise the tool prepared prior to the session to capture the progress of Parties' work in the Bangkok session. ${ }^{9}$ Many brackets and options remain in the text.

\section{Interplay between Accounting and Reporting of NDCs}

Ideally, the guidance related to CTU, accounting, and reporting of NDCs will be robust and provide sufficient detail and accuracy so that the Paris Agreement's aims and principles are met and there is con- 
fidence in Parties' individual and collective effort. However, progress remains uneven. This section examines the tradeoffs between progress made on guidance related to each of the abovementioned areas: CTU, accounting, and reporting on NDCs. It outlines the implications of weaker guidance in one area on the need for greater requirements in the other areas. See Table 1 for a summary of such scenarios.

\section{Insufficient Guidance Related to Information Necessary for CTU of NDCs}

If insufficient guidance is agreed for information necessary for CTU of NDCs, it will be critical that information on the NDC, including its underlying assumptions and methodologies, not only be captured as part of Parties' reporting under Article 13, paragraph $7(\mathrm{~b})$, but also be captured early enough so that it can inform accounting and tracking of progress. Such an approach could resemble an initial report under the Kyoto Protocol, which provided enough information about the Parties' commitment to enable the tracking of progress toward it. ${ }^{10}$ There are several complications with this, however. First, the guidance for reporting under negotiation may not take into account weak outcomes of guidance related to CTU and provide for related reporting requirements. Second, unlike with information for CTU, if such information is reported under Article 13, there would be a time lag between NDC communication and the information provided on the NDC. Under the Kyoto Protocol, the initial report was communicated to the UNFCCC after the determination of a Party's commitment. If the same approach were used for NDCs, and further information on the NDC was communicated with the first biennial transparency report, this would be several years after the NDC would have been communicated.

It is worth mentioning another way insufficient CTU guidance could be mitigated through strengthening of other Agreement provisions. If future accounting guidance constrains choices (e.g., with regard to requiring quantification of NDCs for those that use ITMOs, reference level calculations, land use accounting methods, and/or others), then some information may not be needed when the NDC is communicated, as there would be more consistency across Parties. For example, given the complications of transferring ITMOs calculated with different global warming potentials (GWPs), if the accounting guidance constrained GWP choice for those Parties engaging in ITMOs, those Parties would not necessarily have to provide information on their GWP as part of their NDC, as GWPs would be harmonized across these countries. However, accounting guidance, even if it constrains some choices, will not constrain all choices, given the 'nationally determined' nature of NDCs, necessitating strong information for CTU of NDCs, at least for those aspects of NDCs that are not constrained by accounting guidance. Also, accounting guidance is only to be voluntarily applied to the first NDCs.

\section{Weak Accounting Guidance}

If accounting guidance is not sufficiently detailed to ensure accurate, consistent, and comparable tracking of progress and achievement, there will need to be more reported information under the Paris Agreement's transparency provisions. It may also require new processes. For example, when convergence has not been possible in the past, e.g. in the case of developing forest management reference levels, a transparent process for technical review provided more standardization and safeguards.

Additionally, if accounting guidance is weak or lacking in certain areas, guidance related to CTU would need to be more detailed to ensure sufficient detail is provided on assumed accounting methods, which would be nationally determined in this scenario. This would allow for other Parties and reviewers to have further information for the basis of assessing the NDC and progress made towards its achievement.

While there is an important interplay between accounting and reporting, it should be noted that reporting alone will not be sufficient to make up for the absence of accounting guidance. Weak accounting guidance will lead to significant divergence across Parties' methods for tracking NDC progress

10 Cynthia Elliott, Kelly Levin, Joe Thwaites, Kathleen Mogelgaard, and Yamide Dagnet, 'Designing the Enhanced Transparency Framework: Reporting under the Paris Agreement' (2017) Working Paper. Washington, DC: Project for Advancing Climate Action Transparency (PACT). 
Table 1: Ways to compensate for weak guidance on CTU, accounting or reporting

\begin{tabular}{|l|l|l|l|}
\hline & CTU Guidance & Accounting Guidance & Reporting Guidance \\
\hline Scenario 1 & Insufficient & $\begin{array}{l}\text { Stronger accounting guidance which } \\
\text { constrains Parties' choices so that } \\
\text { less information on assumptions } \\
\text { and methodologies is necessary }\end{array}$ & $\begin{array}{l}\text { Information on NDCs, including } \\
\text { assumptions and methodologies, to } \\
\text { be reported under Article 13 as part } \\
\text { of first biennial transparency re- } \\
\text { port }\end{array}$ \\
\hline Scenario 2 & $\begin{array}{l}\text { More upfront information on } \\
\text { accounting assumptions and } \\
\text { methodologies necessary }\end{array}$ & Insufficient & $\begin{array}{l}\text { More detailed reporting necessary } \\
\text { on outcomes of accounting, as well } \\
\text { as assumptions and methodologies. } \\
\text { Further review procedures likely } \\
\text { necessary. }\end{array}$ \\
\hline Scenario 3 & $\begin{array}{l}\text { Further information necessary } \\
\text { so that independent efforts } \\
\text { can assess progress }\end{array}$ & $\begin{array}{l}\text { Accounting-related information cap- } \\
\text { tured in another vehicle; stronger } \\
\text { accounting guidance which con- } \\
\text { strains Parties' choices so that } \\
\text { progress can be understood }\end{array}$ & \begin{tabular}{l} 
Insufficient \\
\hline
\end{tabular}
\end{tabular}

and achievement, compromising comparability. Importantly, if there are no limits to the flexibility of Parties' accounting approaches, Parties can take advantage of faulty methods that make it appear NDCs are being achieved, when they are not, or suggest that emissions reductions resulted, when they are, in fact, not reflective of what the atmosphere 'sees.'

\section{Insufficient Guidance Related to Reporting on NDC Progress and Achievement}

In the event that Parties agree on insufficient guidance for reporting on NDC progress and achievement, accounting guidance would have to be all the stronger and constrain Parties' choices if progress is to be understood. For example, if Parties have limited choices regarding baseline scenario recalculations, less information would need to be reported accordingly. In other words, the fewer methodological choices that the accounting guidance provides Parties, the more standardization there is across Parties' approaches to tracking progress, and the less information Parties would need to report to understand NDC progress and achievement.

There is also a possible avenue in which accounting-related information is captured elsewhere. For example, if an 'accounting balance sheet' is used by Parties for reporting progress, it could be submitted through another reporting vehicle, to be determined under accounting-related negotiations.

Nevertheless, even with strong accounting that limits Parties' flexibility on accounting approaches and other reporting vehicles, compromised reporting under Article 13, paragraph 7 (b) can lead to an erosion of trust among Parties and in the Paris Agreement itself.

\section{Conclusion}

Each of the guidance documents under development - regarding information necessary for CTU of NDCs, accounting, and reporting of progress and achievement towards NDCs - fulfills separate objectives. Guidance related to information necessary for CTU of NDCs will provide critical upfront information on the NDCs and their assumptions, which forms the basis of accounting and reporting and is critical for building trust among Parties. Accounting guidance will be necessary for understanding the emissions reduction implications of the NDCs and tracking progress and achievement in a consistent and accurate manner. And reporting on progress and achievement of NDCs allows other Parties and reviewers to 
understand whether Parties are on track to meet their commitments, which is at the heart of delivering on the Paris Agreement.

This article has illustrated the consequences of developing weak guidance on CTU, accounting or reporting on the design of guidance in the other areas. While stronger guidance for one of these areas can help make up for weaker guidance in another, each guidance fulfills unique purposes. Accordingly, it is not possible for the other two sets of guidance to completely make up for deficient guidance in the other area. Ideally Parties can come together at $\mathrm{COP} 24$ to agree on robust guidance for all three areas. Only then will we have sufficient understanding of the NDCs, have confidence that they are being accounted for accurately, and have information on their progress and achievement. The Paris Agreement's success rests on such capabilities. 